\title{
CENTRALIDADES MUNICIPAIS E REGIONAIS NA OFERTA DO ENSINO SUPERIOR NO BRASIL
}

\author{
Rafael Santiago Soares ${ }^{1}$
}

Carlos F. Lobo ${ }^{2}$

\section{1- INTRODUÇÃO}

Promulgada no ano de 1996, a mais recente Lei de Diretrizes e Bases da Educação Nacional - LDB favoreceu transformações estruturais nos diferentes níveis de ensino no Brasil. Na educação superior uma das novidades foi a abertura ao capital privado para que pudesse dirigir Instituições de Ensino Superior - IES com fins lucrativos. Outra inovação é a criação do grau de Centro Universitário e sua vinculação prioritária ao ensino e a extensão em detrimento da pesquisa.

Essa parametrização aliada com momentos de crescimento econômico, financiamento estatal, subsídios aos discentes e programas de reestruturação das IES públicas federais fizeram com que o país observa-se um crescimento expressivo nas matrículas no ensino superior. Entre 2000 e 2010, a taxa de crescimento de matrículas no ensino superior foi de $138 \%{ }^{3}$. Diante do crescimento exponencial das matrículas surgiram questionamentos relativos às dimensões educacionais e pedagógicas; ao papel das IES privadas e públicas; e aos elevados índices de lucratividade dos grandes grupos educacionais ${ }^{4}$.

Aqui, acrescenta-se a essas indagações questionamentos sobre os impactos socioeconômicos e regionais de tal expansão. Quais seriam os padrões espaciais e regionais da flexibilização e crescimento da oferta do ensino superior? Quais os municípios que são centralidades na oferta do ensino superior no interior do país? Este artigo é um primeiro - e ainda pequeno - esforço analítico em busca de uma maior compreensão sobre a Geografia regional da flexibilização da oferta do ensino superior no Brasil. O objetivo deste trabalho é identificar os municípios e as regiões referenciais na oferta do ensino superior no interior do Brasil no ano de 2010.

A partir da interpretação de quatro dimensões analíticas que, em parte, serão realizadas por meio da construção de índices, espera-se ser possível a realização de uma

\footnotetext{
${ }^{1}$ Doutorando em Geografia - UFMG

${ }^{2}$ Doutor em Geografia - UFMG

${ }^{3}$ Conforme dados do Censo Superior da Educação do Instituto Nacional de Pesquisa Educacionais Anísio Teixeira - INEP.

${ }^{4}$ Ver, por exemplo, Sampaio (2014).

Cadernos do Leste
}

Artigos Cientificos

Belo Horizonte, Jan.-Dez. Vol.17, n¹7, 2017 
leitura espacial da distribuição de municípios e regiões de destaque na oferta do ensino superior. Este trabalho abre para o debate a discussão sobre os impactos socioespaciais decorrentes dos processos de expansão das IES no Brasil. O ano de 2010 foi tomado como referência, pois permitirá o cruzamento de informações do Censo Demográfico do IBGE com o Censo da Educação Superior do INEP. Entre a aprovação da LDB, em 1996, e o ano de 2010 mudanças estruturais nas formas de oferta do ensino superior no país foram observadas, o que também justifica a escolha desse ano como referência temporal.

A hipótese é de que os centros urbanos de maior hierarquia sejam as referências na oferta do ensino superior. Contudo, novas centralidades podem estar emergindo favorecidas pela flexibilização da oferta e impulsionando reestruturações espaciais e regionais. Haveria, neste sentido, um misto de reforço de antigas centralidades regionais e novos espaços de referência.

\section{2- O CONTEXTO DA FLEXIBILIZAÇÃO E DO CRESCIMENTO DA OFERTA DO ENSINO SUPERIOR NO BRASIL}

O conceito de integração competitiva pautou diversas reformas no Estado brasileiro na década de 1990. Nesse ideário a intencionalidade era integrar o Brasil à dinâmica de globalização econômica e integração regional. A partir disso a política estabelecida pelo Estado proveu uma série de medidas como, por exemplo, as reformas econômicas para a estabilização monetária, a liberalização cambial, a liberalização de importações, a abertura comercial, a privatização de empresas estatais e a renegociação da dívida externa (VIGEVANI, 2004).

No caso em particular, da educação superior brasileira, observam-se novos conteúdos nas legislações e políticas públicas, na natureza das instituições e, acredita-se, também nas formas de impacto e organização regional do setor. Assim como em outras políticas setoriais, a educação teve reformulada a legislação que fornece os parâmetros para o seu funcionamento.

Expressão maior da reestruturação do ensino superior privado no país, perante os novos preceitos sociais, a Lei de Diretrizes e Bases da Educação Nacional - LDB é marco regulatório da educação nacional. A normatização definiu a autonomia para as Universidades e Centros Universitários, dando a prerrogativa a ambos de planejarem e executarem a oferta de cursos e vagas sem uma prévia autorização do poder público. 
A LDB foi o instrumento normativo que estruturou e permitiu a entrada do capital privado na educação superior brasileira. De acordo com Schwartzman e Schwartzman (2002), a legislação considerou a busca pelo lucro nas instituições não mais como antagônica e o setor privado um parceiro para a consecução dos objetivos educacionais. A maior facilidade para a abertura de instituições de ensino superior privado é destacada pelos autores, para os quais o exame das condições iniciais de oferta se pautam em itens de infraestrutura física, sendo a composição do corpo docente e os projetos pedagógicos analisados com base em promessas e intenções.

Uma importante interface entre o público e o privado emerge nesse processo: a quebra da resistência do subsídio público à educação privada. Já nos anos 2000, Schwartzman e Schwartzman indicavam a tendência do crédito educativo como uma forma de subsídio indireto às instituições de ensino. A partir de 2003, com a assumpção do governo brasileiro por Luís Inácio Lula da Silva, as políticas públicas de oferta e financiamento estudantil são reestruturadas. Por um lado, as relações entre público e privado são aprofundadas no âmbito do financiamento estudantil. De outro, nesse governo, houve um reforço do papel da capilaridade das IES - Federais e o estabelecimento de uma política de aumento de vagas nas instituições públicas.

A barreira entre o público e o privado foi verdadeiramente diminuta com a reformulação do FIES - Fundo de Financiamento Estudantil -, a criação do PROUNI Programa Universidade para Todos - e as alterações na forma de entrada de ingressantes por meio do SISU - Sistema de Seleção Unificada do Ministério da Educação. O FIES permitiu que os discentes pudessem financiar até cem por cento das suas mensalidades, com juros baixos - 3,4\% a.a., carência para pagamento das primeiras parcelas de dezoito meses e amortização da dívida em três vezes o período de financiamento. O crescimento do FIES foi expressivo nas últimas décadas: entre 1999 e 2009, 600 mil contratos foram formalizados; de 2010 à 2013, o FIES atingiu a marca de 1 milhão e 100 mil formalizações; e, em 2014, chegou-se a marca 1 milhão e 500 mil contratos. O PROUNI e o SISU unificaram a seleção de estudantes por meio do ENEM - Exame Nacional do Ensino Médio - e permitiram a consecução de bolsas de estudos, em instituições privadas, que chegam até cem por cento do valor da mensalidade.

Além de fomentar o aprofundamento das relações entre o poder público e o privado, os governos do PT patrocinaram uma importante política de reestruturação da educação superior pública federal. Consoante SESu (2014, p. 31) a expansão das instituições federais de ensino seguiram três frentes de ação: interiorização; integração e regionalização Cadernos do Leste 
do ensino superior. Em 2007, a ampliação passa a ser direcionada pelo Programa de Reestruturação e Expansão das Instituições Federais de Ensino Superior - REUNI. O escopo do REUNI contemplava o aumento de vagas nos cursos de graduação, a ampliação da oferta de cursos noturnos, a promoção de inovações pedagógicas e o combate à evasão.

\section{3- MUNICÍPIOS E REGIÕES REFERENCIAIS NA OFERTA DO ENSINO SUPERIOR: UNIDADES ESPACIAIS DE ANÁLISE E PROCEDIMENTOS METODOLÓGICOS ADOTADOS}

No intuito de identificar os municípios e as regiões referenciais na oferta do ensino superior no Brasil, adotou-se os municípios como unidades espaciais iniciais de análise. Essa referência espacial permitiu o estabelecimento de um exame comparativo com as cinco grandes regiões brasileiras definidas pelo IBGE e com as hierarquias urbanas estabelecidas pela REGIC - Região de Influência das Cidades (2007).

Definidas pelo IBGE em 1970, as cinco grandes regiões brasileiras - Norte, Nordeste, Centro-Oeste, Sudeste e Sul - são resultantes de uma regionalização homogênea, que buscou o agrupamento de municípios, respeitando os limites das unidades federativas em grandes unidades. Já o estudo sobre as regiões de influência das Cidades procurou a definição das hierarquias dos centros urbanos e a delimitação das suas respectivas regiões de influência. No seio dessa última regionalização está contida a relação dessas centralidades urbanas com os aspectos de gestão federal e empresarial e a dotação de equipamentos e serviços. Dessa proposta surgiram cinco grandes hierarquias:

a) Metrópole, composta pelos 12 principais centros urbanos do país - São Paulo, Brasília, Rio de Janeiro, Manaus, Belém, Fortaleza, Recife, Salvador, Belo Horizonte, Curitiba, Goiânia e Porto Alegre; b) Capital Regional, integram essa hierarquia 70 centros que possuem relação direta com o extrato superior da REGIC; c) Centro Sub-Regional, constituído por 169 municípios que apresentam atividades de gestão menos complexas; d) Centro de Zona - 556 cidades de menor porte formam esse nível, possuindo processos de gestão mais elementares; e) finalmente, os centros locais, os demais 4.473 municípios compõem esse extrato, nos quais o nível de gestão e influência está contido apenas no próprio limite municipal (IBGE, 2008) ${ }^{5}$.

Inicialmente, explorou-se o crescimento do ensino superior entre os anos de $2000 \mathrm{e}$ 2010, incluindo as capitais de estado e os municípios em Regiões Metropolitanas das sedes

\footnotetext{
${ }^{5}$ Os níveis da REGIC possuem subdivisões de acordo com a capacidade dos centros urbanos em exercer papeis de gestão. Para uma análise mais detalhada ver IBGE (2008).

Cadernos do Leste

Artigos Cientificos

Belo Horizonte, Jan.-Dez. Vol.17, n¹7, 2017
} 
administrativas da unidade da federação. Esse procedimento permitiu a identificação das tendências de crescimento regional e a distribuição das matrículas entre as hierarquias da REGIC com um todo.

Em seguida, trabalhou-se, com quatro dimensões para avaliar os municípios e regiões referenciais na oferta do ensino superior no interior do país. O primeiro é a quantidade de matrículas, que é um fator preponderante para identificação de centros referenciais na oferta do ensino superior. A maior ou menor concentração desse atributo expressa fortemente o papel exercido pela localidade no âmbito do oferecimento desse serviço. Neste caso, levou-se em consideração o número total de matriculados por município. O total de cursos coloca em evidência a diversificação de IES e de cursos de graduação em um município. Para essa dimensão foi adotado o mesmo procedimento anterior, ou seja, utilizou-se o número total de cursos. Avaliou-se também a capacidade de absorção de pessoas com ensino médio completo do próprio município, por meio da divisão entre as pessoas que declararam estar cursando o ensino superior pelo total de pessoas com ensino médio completo. E, por último, analisou-se a capacidade de atração de pessoas de outras localidades, dimensão esta que denota o papel de atração das IES e dos municípios. Subtraiu-se o total de matriculados em IES por município pelo total de pessoas que declararam estar cursando ensino superior na mesma localidade em que reside. Em seguida, dividiu-se este produto, que representa a população matriculada em um município, mas que reside em outra localidade, pelo total de pessoas que declararam cursar o ensino superior. Em consonância com os objetivos foram extraídos dos cálculos os municípios que não possuíam IES e, por consequência, matrículas; os localizados em Regiões Metropolitanas das sedes administrativas das Unidades da Federação; e todas as capitais de estado.

Os produtos de todas essas dimensões foram convertidos em um índice (I_v^d), conforme a seguinte expressão:

$$
I_{v}^{d}=\frac{v_{i}-v_{\min }}{v_{\max }-v_{\min }}
$$

Sendo que: $v_{i}=$ enésimo valor observado na variável "v"; $v_{\min }=$ valor mínimo observado na variável "v"; $v_{\max }=$ valor máximo observado na variável "v".

Assim, os quatro parâmetros foram sintetizados em um índice que varia entre 0 e 1 , representando, respectivamente, os municípios que exercem menor ou maior força nas dimensões explicitadas (ver figuras 1 a 4, destacadas abaixo). O Índice de Centralidade na Cadernos do Leste 
Oferta do Ensino Superior é produto da média desses quatro outros indicadores.Foram criadas cinco classes para este índice, a saber: Muito Alto, Alto, Médio, Baixo e Muito Baixo.

Após a obtenção do Índice de Centralidade na Oferta do Ensino Superior, com a finalidade de apontamento de concentração de municípios referenciais, aplicou-se o Índice de Moran Local (LISA). Esse procedimento identifica agrupamentos estatisticamente
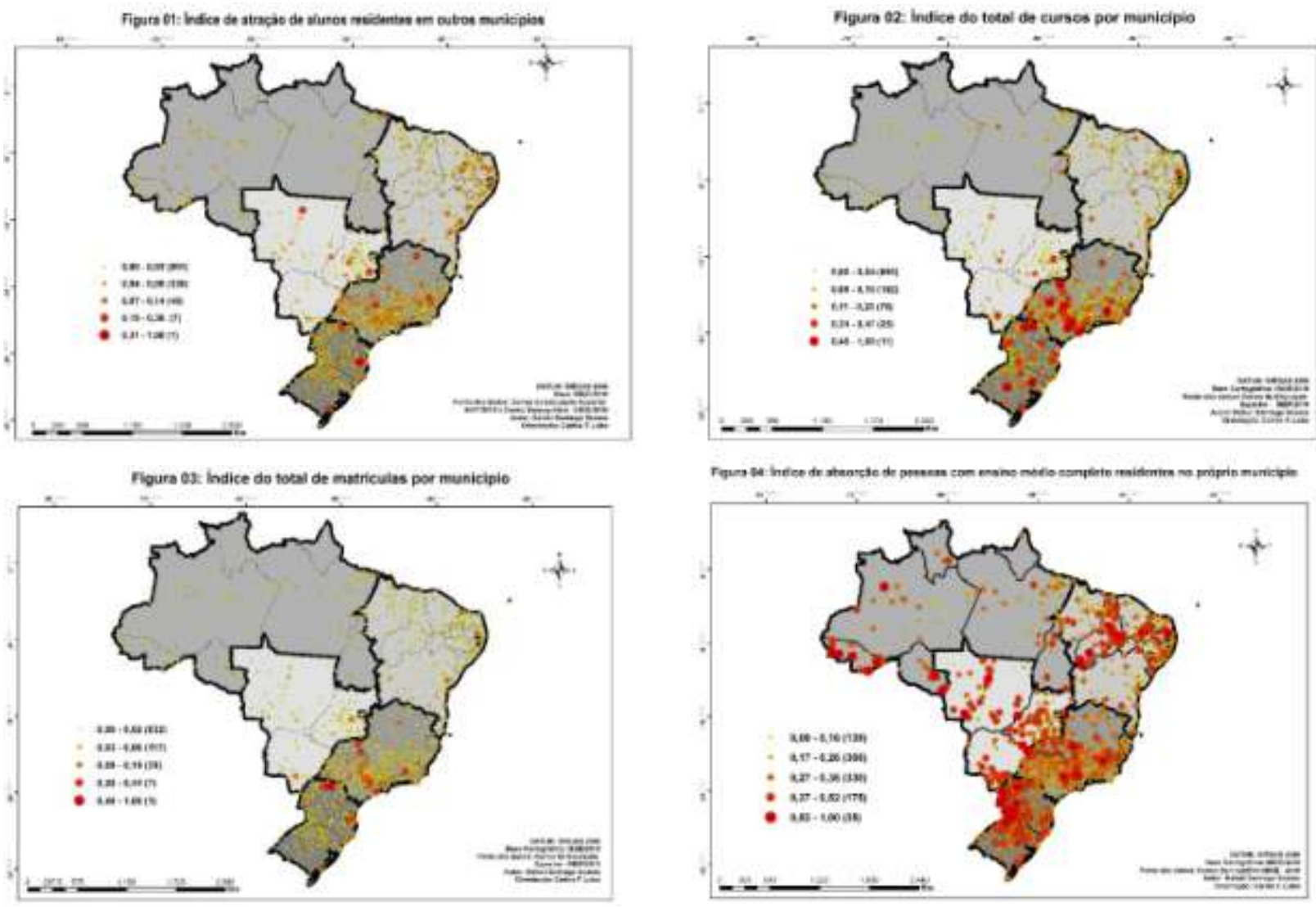

significantes e permite o aprofundamento da análise e da dependência espacial, por meio do seguinte cálculo:

$$
I_{i}=\left(\frac{x_{i}-\mu}{\frac{\left(\sum\left(x_{i-} \mu\right)^{2}\right)}{N}}\right) \sum_{j} w_{i j}\left(x_{j}-\mu\right)
$$

Onde: $I_{i}=$ Moran Local para a observação; $N=$ número de observações; $\mathrm{x}=$ variável analisada; $\mu=$ média de $\mathrm{x} ; w_{i j}=$ elemento da matriz de pesos espaciais, nos quais há presença da referência espacial. O mapa resposta apresenta cinco agrupamentos: espaços não-significantes, nos quais não há um padrão de distribuição espacial; baixobaixo, composto por espaços de referência com valor baixo e o entorno também baixo; baixo-alto, Cadernos do Leste 
o espaço de referência é baixo, mas seus vizinhos são altos; alto-baixo, espaços constituídos por um valor elevado, mas com áreas próximas baixas; alto-alto, espaços com altos índices com vizinhos com a mesma característica.

\section{4- MUNICÍPIOS E REGIÕES REFERENCIAIS NA OFERTA DO ENSINO SUPERIOR: PRIMEIROS APONTAMENTOS}

O crescimento da oferta do ensino superior no Brasil possui nuances regionais que merecem destaque. Entre os anos 2000 e 2010, o Nordeste aumentou sua proporção no número total de matriculados em 4,81\%. De 15,37\% essa região passou para 20,17\% do total de matriculados no país. As regiões Sul e Sudeste diminuíram sua proporção respectivamente de 20,13\% para 16,63\% e 51,86\% para 49,07\%. O Centro-Oeste praticamente manteve sua proporção de $8,39 \%{ }^{6}$. As taxas de crescimento por região também indicam novas tendências. A maior expansão na oferta é o da região Norte com $219,98 \%$ entre 2000 e 2010 . O Nordeste apresenta o segundo maior crescimento com 212,98\%. Centro-Oeste, Sudeste e Sul cresceram nessa ordem: 138,02\%, 124,89\% e 96,31\%.

Se considerando as grandes regiões brasileiras foi possível identificar significativas distinções, ao levar em conta a hierarquia da REGIC o padrão de distribuição de matrículas apresenta poucas mudanças. Destaca-se a diferença da hierarquia capital Regional, que em 2000 possuía 27\% e em 2010 atingiu 30\% do total de matrículas. As demais localidades variaram em torno de $1 \%$ para mais ou para menos.

As taxas de crescimentos de matrículas apontam para diferenças em relação ao padrão de distribuição. No período analisado, as Capitais Regionais cresceram em um ritmo maior, atingindo a taxa de 164,44\% seguidas pelos Centros de Zona com 144,75\%. As metrópoles e os Centros Locais aparecem em seguida com 129,96\% e 127,66\%. O menor crescimento é dos Centros Sub-Regionais com 111,01\%.

\footnotetext{
${ }^{6}$ É importante destacar que não há grandes diferenças no crescimento populacional que possam justificar o aumento expressivo da região Nordeste, conforme os dados dos Censos Demográficos de 2000 e 2010. Cadernos do Leste 
Gráfico 01 - Crescimento de matrículas por hierarquias da REGIC entre 2000 e 2010

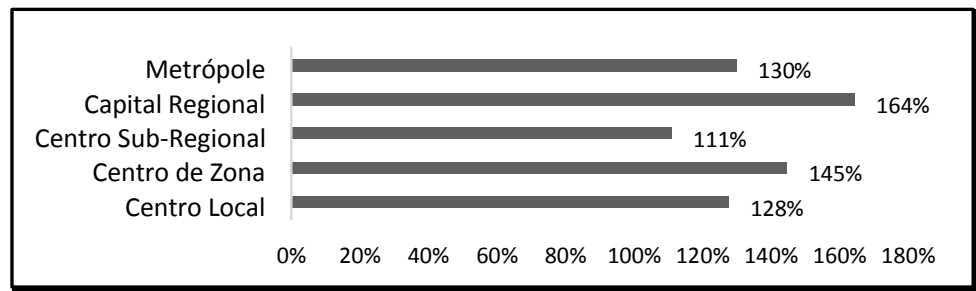

Fonte: Elaborado pelo autor com base nos dados do Censo do Ensino Superior _ INEP (2000 e 2010)

Essa descrição dos padrões de distribuição das matrículas em relação ao total e das taxas de crescimento, tanto em relação às grandes regiões brasileiras quanto à hierarquia da REGIC, fortalecem o argumento da hipótese deste trabalho. Os dados corroboram a afirmação de que a flexibilização da oferta do ensino superior favoreceu um duplo movimento, ou seja, a continuidade da concentração em áreas já consolidadas como a região Sudeste e as Metrópoles, concomitantemente, à expansão em novas localidades e regiões.

O Índice de Centralidade na Oferta do Ensino Superior (Figura 05) - que levou em consideração apenas os municípios do interior do país - também contribui para a reflexão. As quatro dimensões problematizadas - número total de cursos, número total de matrículas, poder de absorção pelas IES de pessoas com ensino médio completo do próprio município e poder de atração das IES de pessoas de outros municípios - indicam tendências que também vão em direção da hipótese que norteou o artigo. Dentre os dez primeiros ranqueados pelo índice, todos são da região Sudeste e oito são classificados como Capitais Regionais (Tabela 01).

Figura 05 - Índice de centralidade na oferta do ensino superior no Brasil

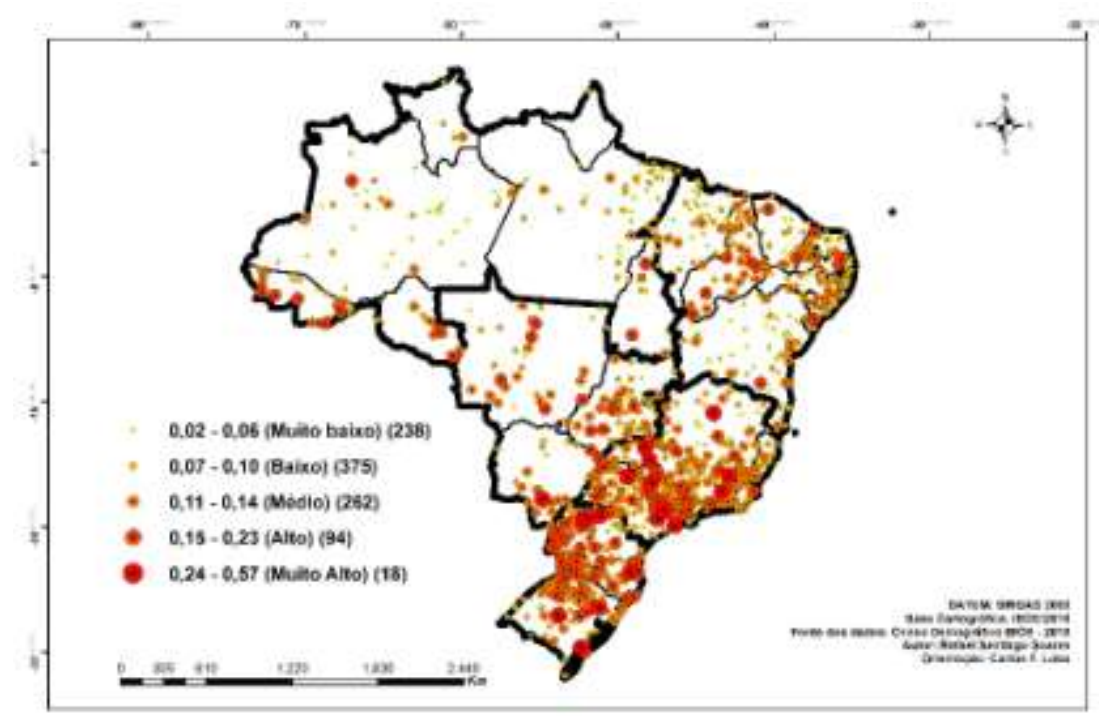


Tabela 01 - Dez primeiros municípios no Índice de Centralidade na Oferta do Ensino Superior

\begin{tabular}{c|l|c|c}
\hline UF & MUNICÍPIO & $\begin{array}{l}\text { HIERARQUIA - } \\
\text { REGIC }\end{array}$ & ÍNDICE \\
\hline PR & Londrina (PR) & Capital Regional & 0,57 \\
\hline SP & Campinas (SP) & Capital Regional & 0,46 \\
\hline SC & Indaial (SC) & Centro de Zona & 0,44 \\
\hline MG & Uberlândia (MG) & Capital Regional & 0,34 \\
\hline SP & Ribeirão Preto (SP) & Capital Regional & 0,31 \\
\hline PR & Maringá (PR) & Capital Regional & 0,31 \\
\hline MG & Uberaba (MG) & Capital Regional & 0,30 \\
\hline SP & Santos (SP) & Capital Regional & 0,30 \\
\hline RS & Caxias do Sul (RS) & Capital Regional & 0,30 \\
\hline RS & Santa Maria (RS) & Centro Local & 0,29 \\
\hline
\end{tabular}

Fonte: Elaborado pelo autor, com base nos dados do Censo da Educação Superior INEP (2010) e do Censo Demográfico do IBGE (2010)

As regiões Norte e Nordeste não possuem municípios classificados no índice como Muito Alto, e mais de 70\% dos municípios com a presença de IES estão na faixa de baixo ou muito baixo. A Sudeste e a Sul contêm 3,05\% e 3,43\% de localidades identificadas como Muito Alto, nessa ordem. Nestas duas regiões, a maior concentração de municípios está na faixa denominada Médio. A Centro-Oeste é o destaque na classificação médio, na qual se observa 33,02\% dos municípios presentes nessa categoria. A região Sul merece destacamento pois possui mais municípios proporcionalmente nos conjuntos Muito Alto, Alto e Médio e o menor no Muito Baixo.

No âmbito da hierarquização da REGIC é preponderante a associação entre Capitais Regionais e o padrão Muito Alto e Alto, 58\% dessas localidades estão neste perfil do índice. Do restante dos municípios, 30\% possuem o indicador Médio e 11,67\% Baixo, não havendo Capitais Regionais classificadas como Muito baixo. A hierarquização a partir das faixas do índice se assemelham com as da REGIC. O segundo destaque, por exemplo, são os Centros Sub-Regionais. Essas localidades não apresentam nenhum município classificado com Muito Alto, contudo, 47,77\% destes estão entre Alto e Médio, valores acima das demais hierarquias. Os menores índices de centralidade são observados nos Centros Locais, onde $80,29 \%$ dos municípios com IES estão enquadrados como Baixo ou Muito Baixo.

A descrição da distribuição da classificação do índice designa que as maiores centralidades de oferta do ensino superior estão concentradas nas principais regiões econômicas do país, Sul e Sudeste, e nos principais centros urbanos, ou seja, nas Capitais Regionais. 
A partir da espacialização do índice e a elaboração de clusters construídos por meio do método Moran Local - LISA (Figura 06) foi possível a identificação de concentrações (regiões) e comparar as suas inserções nas grandes regiões brasileiras e nas hierarquias urbanas da REGIC.

Figura 06 - Agrupamentos de municípios a partir do índice de centralidade na oferta do ensino superior

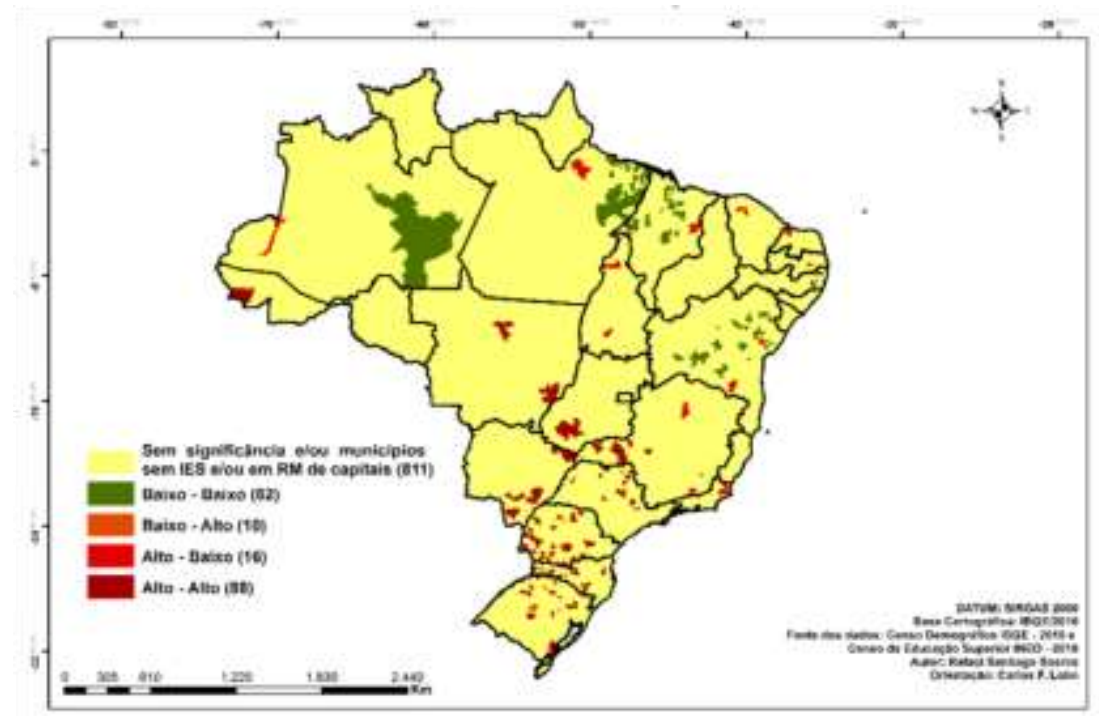

Novamente, a região Sul é destaque ao conter 28\% dos municípios com IES em agrupamentos Alto-Alto. A Centro-Oeste com 11\% das localidades inseridas em cluster Alto-Alto também possui relevância no resultado dessa clusterização, mesmo com o número de municípios com IES inferiores às regiões Sul e Sudeste. As regiões Norte e Nordeste se destacam pela quantidade de aglomerações do tipo baixo-alto; a primeira possui $28 \%$ nessa classificação e a segunda $20 \%$. No Sudeste é expressivo os $20 \%$ de municípios contidos em agrupamentos do tipo Baixo-Alto.

Em relação ao resultado da aplicação do método LISA e sua comparação com a hierarquia da REGIC, ressalta-se a concentração de Capitais Regionais situadas nas classes Alto-Alto e Alto-Baixo, para ser mais preciso 46,67\% destas localidades. Logo após os Centros Sub-Regionais, com 18,47\% também presentes nessa faixa do resultado do modelo. Os Centros de Zona e os Locais possuem porcentagens menores nas maiores classes do resultado do LISA, contendo, respectivamente, 6,13\% e 5,60\% de Alto-Alto e não possuindo nenhum Alto-Baixo.

Os mapas com a representação da distribuição do Índice de Centralidade na Oferta do Ensino Superior e com os agrupamentos resultantes do método LISA colocam em evidência dois vetores de concentração de força da oferta do ensino superior no interior do Cadernos do Leste 
país. O primeiro é um vetor de Sudeste para Noroeste, originando-se entre São Paulo e Minas Gerais, passando pelo Triângulo Mineiro e Goiás até o estado de Mato Grosso.

O segundo no Oeste dos estados do Sul do Brasil em direção até o Mato Grosso do Sul.

\section{5- CONSIDERAÇÕES FINAIS}

Os resultados da análise da oferta de matrícula entre os anos 2000 e 2010 e da interpretação da distribuição espacial do Índice apresentam tendências na organização espacial desse processo. O crescimento da participação de Nordeste e de Norte na proporção de matriculados total é uma das constatações. Assim como a manutenção de uma estrutura concentrada, principalmente, na região Sudeste. Apesar de o crescimento de Nordeste e Norte, o índice e os agrupamentos do LISA identificam a baixa centralidade na oferta do ensino superior dos municípios dessas regiões. A região Sul sobressai tanto no índice mais elevado dos seus municípios como na concentração de clusters Alto-Alto, mesmo sendo a região que mais perdeu participação no total de matriculados.

Se há mudanças nos padrões de distribuição das matrículas nas grandes regiões brasileiras o mesmo não pode ser repetido para as hierarquias urbanas da REGIC, com exceção das Capitais Regionais. De uma maneira geral, os dados confirmam a manutenção da distribuição entre os centros urbanos da REGIC, não havendo alterações estruturais. $\mathrm{O}$ produto do índice e do método Moran Local mostram a proeminência das Capitais Regionais na centralidade na oferta do ensino superior, mesmo diante um processo de interiorização e do crescimento significativo das matrículas nos Centros de Zona.

Essas constatações vão na direção da proposição da hipótese apresentada na introdução, ou seja, os centros urbanos de maior hierarquia como as referências na oferta do ensino superior no interior do país. Não obstante, acompanhados de novas centralidades favorecidas pela flexibilização e crescimento da oferta. A problematização do crescimento das matrículas e as análises do Índice de centralidade na oferta do ensino superior, no âmbito das grandes regiões e da hierarquia da REGIC, permitem a constatação da validade da hipótese.

Todavia, o texto introduz uma temática que carece de maior aprofundamento analítico e confrontação teórica com as demais interpretações das novas espacialidades das atividades econômicas e dinâmicas populacionais no território brasileiro. Além de a avaliação dos impactos socioespaciais da flexibilização e crescimento da oferta do ensino superior. Tarefa de maior robustez e a ser desenvolvida em maior tempo e espaço. 


\section{REFERÊNCIAS BIBLIOGRÁFICAS}

INSTITUTO BRASILEIRO DE GEOGRAFIA E ESTATÍSTICA - IBGE. Censo

Demográfico - 2010. Rio de Janeiro: IBGE, 2010.

INSTITUTO BRASILEIRO DE GEOGRAFIA E ESTATÍSTICA - IBGE. Regiões de influência das cidades 2007. Rio de Janeiro: IBGE. 2008.

INSTITUTO NACIONAL DE ESTUDOS E PESQUISAS EDUCACIONAIS ANÍSIO TEIXEIRA - INEP. Censo Demográfico da Educação Superior 2000 e 2010. Brasília: INEP, 2012.

SAMPAIO, H. O ensino superior privado: tendências das últimas décadas. São Paulo: Universidade de São Paulo, 2014.

SESu - SECRETARIA DE EDUCAÇÃO SUPERIOR / MEC. A democratização e expansão da educação superior no país: 2003 - 2014. Brasília: MEC, 2014.

ROGERSON, P. A. Métodos estatísticos para Geografia. Porto Alegre: Bookman, 2012, $3^{\circ}$ edição.

SAMPAIO, H. O global e o local no ensino superior no Brasil: apontamentos preliminares. Caxambu: ANPOCS, 2014, p. 01-37.

SCHWARTZMAN, J; SCHWARTZMAN, S. O ensino superior privado como setor econômico. BNDES, Brasília, 2002.

VIGEVANI, T. A política externa na era FHC: um exercício de autonomia pela integração. Revista Internacional Interdisciplinar Interthesis, Florianópolis, v. 15, n. 02, nov. 2004, p. 31-61. 